\title{
Refinement issue of displaced volume at upsetting of cylindrical workpiece by radial dies
}

\author{
Viktor Artiukh ${ }^{1 *}$, Volodymyr Kukhar ${ }^{2}$, and Elena Balalayeva ${ }^{2}$ \\ ${ }^{1}$ Peter the Great St. Petersburg Polytechnic University, Polytechnicheskaya, 29, St.Petersburg, \\ 195251, Russia \\ ${ }^{2}$ Pryazovskyi State Technical University, Universytets'ka, 7, Mariupol, 87500, Ukraine
}

\begin{abstract}
By analyzing the problem of upsetting of a workpiece by radial dies, an improved solution for determining the displaced volume was obtained. The value of the displaced volume is the basis for calculating such an important technological criterion as the engineering strain range of the workpiece during the upsetting. It is revealed that the main difficulty lies in calculating the volume that is placed between the contact surface and the end protuberances of the deformed workpiece, which requires the involvement of numerical or tabular integration methods that do not provide a complete solution.
\end{abstract}

\section{Introduction}

The difficulties associated with the need for preforming operations in the stamped space of presses require the search for universal low-tooling methods of shaping the blanks before making forgings of a complicated configuration [1-5]. Obtaining profiled semi-finished products for hot-stamp forgings with a simplified shape tool is feasible by increasing the possibilities of operations based on the upsetting [6-8], which most often are inefficiently used only for the purpose of knocking down scale [9]. A number of recent studies in the field of upsetting processes [10-16] confirm a variety of unresolved problems of shaping such a seemingly simple operation.

With the use of preparatory upsetting of workpieces with radial dies (Fig. 1), to improve stamping technology $[4,13,15,17]$, it is necessary to accurately assign the engineering strain range at the upsetting, which has a significant effect on geometric shaping, uneven deformation, energy-strength parameters, choice of thermal conditions and others characteristics.

The engineering strain range during the upsetting is determined by the displaced volume, which calculation represents a separate mathematical problem [16]. Such a solution does not take into account the possibility of transition to polar coordinates when considering the horizontal cross-section of the workpiece.

\footnotetext{
*Corresponding author: artiukh@mail.ru
} 


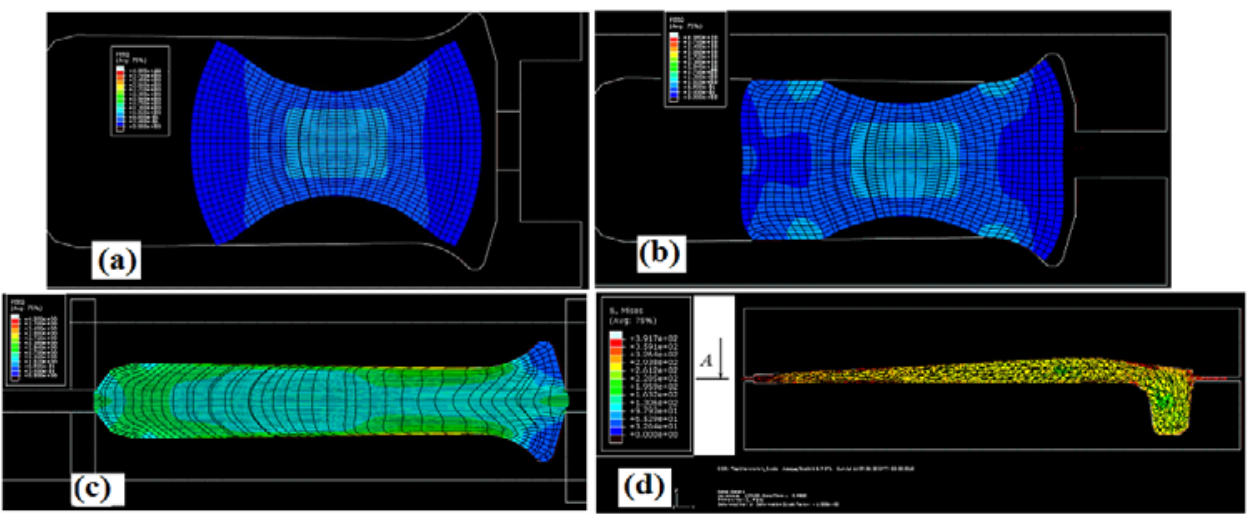

Fig. 1. Modeling of die-forging of "plate" forgings: workpiece upset by radial dies placed in blockimpression (a); intermediate stage (b); blocking (c); finishing (d)

The implementation of such a transition with the simultaneous use of the reserves of intermediate solutions with the help of refined integration in the CAE [18] environment allows more accurate calculation of the displaced volume at the upsetting of cylindrical workpieces by convex elongated dies.

\section{Purpose of the work}

The purpose of this article is to refine the problem of calculating the displaced volume during the introduction of a convex slab into a cylindrical workpiece at the preparatory-procuring transition of stamping.

\section{Methodology}

In connection with the presence of significant unevenness of the deformation along the height of the workpiece, which is being upset by a curved die, the known formula [19-21] becomes inapplicable for estimating the engineering strain:

$$
\varepsilon=\left(\left(H_{0}-h\right) / H_{0}\right) \cdot 100 \% .
$$

where $H_{0}$ and $\mathrm{h}$ are the initial and final height of the workpiece, respectively.

Analytic consideration of the problem of determining the amount of displaced volume when introducing a convex elongated upsetting plate into the end of the workpiece is carried out according to the scheme shown in Fig. 2. We accept the assumption of a central symmetric embedding of a convex elongated plate of radius $R$ into an isotropic cylindrical workpiece with an initial radius $r_{0}$, i.e. the initial diameter of the workpiece is $D_{0}=2 r_{0}$. Forming processes in the upper and lower parts of the workpiece, i.e. with respect to its horizontal axis, are considered symmetrical, which allows us to consider only the upper half of the workpiece. The approximate cross-section of the deformed workpiece is a circle of radius $r$.

The equation of a circle with center $\left(0 ; H_{1}\right)$, describing the projection of a convex upsetting plate with radius $R>r$ on the $y z$ plane according to Fig. 2 is:

$$
\left(z-H_{1}\right)^{2}+y^{2}=R^{2} .
$$




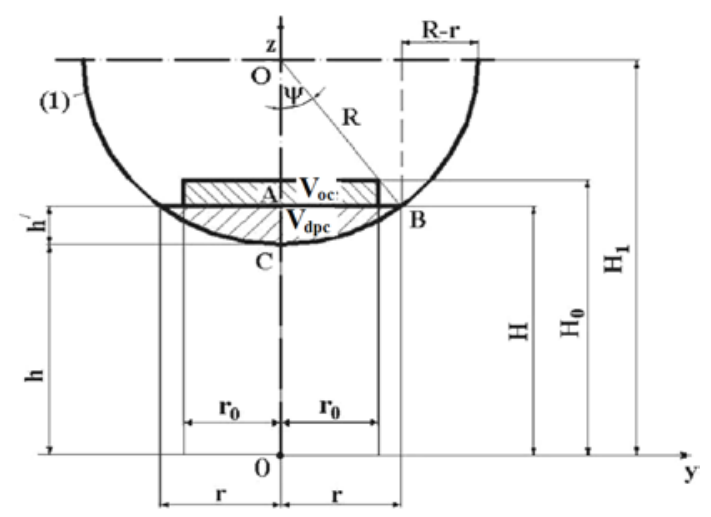

Fig. 2. Calculation scheme of the upsetting of a cylindrical workpiece by radial dies

The volume of the half of the initial cylindrical workpiece is calculated as $V_{w p}=\left(\pi \cdot r_{0}^{2} \cdot H_{0}\right) / 2$. In this case, the displaced volume $\mathrm{V}$ behind the contours of the profiled workpiece can be approximately represented as a sum of two volumes (see Fig. 2):

$$
V=V_{o c}+V_{d p c}
$$

where:

$$
\begin{gathered}
V_{o c}=\pi \cdot r_{0}^{2}\left(H_{0}-H\right) ; \\
V_{d p c}=\iint_{D_{c M}}\left(z_{A}-z_{C}\right) d x d y,
\end{gathered}
$$

where $z_{A}$ and $z_{C}$ are the coordinates along the $0 \mathrm{z}$ axis determined by the points $\mathrm{A}$ and $\mathrm{C}$, namely by the halves of the maximum and minimum height of the workpiece after the introduction of the radius plates;

$D_{d p c}$ is a region of radius $\mathrm{r}$ corresponding to the projection of the contact surface of the radius plate and the upset workpiece onto $x y$ horizontal plane.

From equation (1) we have:

$$
\left(z-H_{1}\right)^{2}=R^{2}-y^{2}
$$

Whence we get:

$$
z=-\sqrt{R^{2}-y^{2}}+H_{1} \text { or } z=H_{1}-\sqrt{R^{2}-y^{2}}
$$

So you can determine the coordinates: $z_{A}=H$ and $z_{C}=H_{1}-\sqrt{R^{2}-y^{2}}$.

Then we write equation (3) as follows:

$$
V_{d p c}=\iint_{D d p c}\left(H-H_{1}-\sqrt{R^{2}-y^{2}}\right) d x d y .
$$

We find: $H_{1}=H+A O$, where from the triangle $\triangle O A B$ we have: $A O=\sqrt{R^{2}-r^{2}}$, whence: 


$$
H=H_{1}-\sqrt{R^{2}-r^{2}} .
$$

Correspondingly, substituting equation (7) into the integral (6), we write:

$$
V_{d p c}=\iint_{D_{d p c}}\left(H_{1}-\sqrt{R^{2}-r^{2}}-H_{1}-\sqrt{R^{2}-y^{2}}\right) d x d y=\iint_{D d p c}\left(\sqrt{R^{2}-y^{2}}-\sqrt{R^{2}-r^{2}}\right) d x d y
$$

To perform the integration, we pass to the polar coordinates:

$$
\left.\begin{array}{cc}
x^{2}+y^{2}=r_{0}^{2} ; & x=\rho \cos \varphi ; y=\rho \sin \varphi \\
\cos ^{2} \varphi+\rho^{2} \sin ^{2} \varphi=r_{0}^{2} ; & \rho=r_{0} ; d x d y=\rho d \rho d \varphi
\end{array}\right\}
$$

Then we have:

$$
V_{d p c}=\int_{0}^{2 \pi} d \varphi \int_{0}^{2 \pi}\left(\sqrt{R^{2}-\rho^{2} \sin ^{2} \varphi}-\sqrt{R^{2}-r^{2}}\right) \rho d \rho
$$

After solving the internal integral using the Mathcad package, we get:

$$
\begin{aligned}
& V_{d p c}=\left.\int_{0}^{2 \pi}\left(\frac{1}{6}\left(\frac{2\left(R^{2}-\rho^{2} \sin ^{2} \varphi\right)^{\frac{3}{2}}}{-\sin ^{2} \varphi}+3 \sqrt{R^{2}-r^{2}} \cdot \rho^{2}\right)\right)\right|_{0} ^{r_{0}} d \varphi= \\
& =\int_{0}^{2 \pi}\left(-\frac{1}{3} \cdot \frac{\left(R^{2}-r_{0}^{2} \sin ^{2} \varphi\right)^{\frac{3}{2}}}{\sin ^{2} \varphi}+\frac{1}{3} \frac{R^{3}}{\sin ^{2} \varphi}+3 \sqrt{R^{2}-r^{2}} \cdot r_{0}^{2}\right) d \varphi .
\end{aligned}
$$

Whence we have:

$$
\begin{aligned}
& V_{d p c}=-\frac{1}{3} \int_{0}^{2 \pi} \frac{\left(R^{2}-r_{0}^{2} \sin ^{2} \varphi\right)^{\frac{3}{2}}}{\sin ^{2} \varphi} d \varphi+\frac{1}{3} \int_{0}^{2 \pi} \frac{R^{3}}{\sin ^{2} \varphi} d \varphi+3 \int_{0}^{2 \pi} \sqrt{R^{2}-r^{2}} \cdot r_{0}^{2} d \varphi= \\
& =-\frac{1}{3} \int_{0}^{2 \pi} \frac{\left(R^{2}-r_{0}^{2} \sin ^{2} \varphi\right)^{\frac{3}{2}}}{\sin ^{2} \varphi} d \varphi-\left.\frac{1}{3} R^{3} \cdot \operatorname{ctg} \varphi\right|_{0} ^{2 \pi}+\left.3 \sqrt{R^{2}-r^{2}} \cdot r_{0}^{2} \cdot \varphi\right|_{0} ^{2 \pi} .
\end{aligned}
$$

In view of the symmetric limits of integration, the average expression $1 / 3 \cdot R^{3} \cdot \operatorname{ctg} \varphi$ of equation (12) is assumed to be zero. Then we write:

$$
V_{d p c}=-\frac{1}{3} \int_{0}^{2 \pi} \frac{\left(R^{2}-r_{0}^{2} \cdot \sin ^{2} \varphi\right)^{\frac{3}{2}}}{\sin ^{2} \varphi} d \varphi+3 \sqrt{R^{2}-r^{2}} \cdot r_{o}^{2} \cdot 2 \pi
$$

We denote the integral of the equation (13) by $\mathrm{J}$ and solve it with the help of changing the variables: 


$$
J=\int \frac{\left(R^{2}-r_{0}^{2} \cdot \sin ^{2} \varphi\right)^{\frac{3}{2}}}{\sin ^{2} \varphi} d \varphi=\left|\begin{array}{l}
t=\operatorname{tg} \varphi ; \quad \varphi=\operatorname{arctg} t \\
d \varphi=\frac{d t}{1+t^{2}} ; \sin ^{2} \varphi=\frac{t^{2}}{1+t^{2}}
\end{array}\right| .
$$

Reflecting the course of the solution, we write:

$$
J=\int \frac{\left(R^{2}-r_{0}^{2} \cdot \frac{t^{2}}{1+t^{2}}\right)^{\frac{3}{2}}}{\frac{t^{2}}{1+t^{2}}} \cdot \frac{d t}{1+t^{2}}=\int \frac{\left(R^{2}\left(1+t^{2}\right)-r_{0}^{2} t^{2}\right)^{\frac{3}{2}}}{t^{2}\left(1+t^{2}\right)^{\frac{3}{2}}} d t=\int \frac{\left(R^{2}+R^{2} t^{2}-r_{0}^{2} t^{2}\right)^{\frac{3}{2}}}{t^{2}\left(1+t^{2}\right)^{\frac{3}{2}}} d t
$$

To take the last integral (15), numerical or tabular methods can be used. For example, solving this integral with Mathcad, we get:

$$
\begin{aligned}
& J=R^{2} \cdot \frac{\sqrt{R^{2}+R^{2} t^{2}-r_{0}^{2} t^{2}}}{t}-\ln \left[t \cdot \sqrt{-R^{2}+r_{0}^{2}}+\sqrt{\left(-R^{2}+r_{0}^{2}\right) t^{2}-R^{2}}\right] \cdot R^{4}+ \\
& +\ln \left[t \cdot \sqrt{-R^{2}+r_{0}^{2}}+\sqrt{\left(-R^{2}+r_{0}^{2}\right) t^{2}-R^{2}}\right] \cdot r_{0}^{2} \cdot R^{2}- \\
& -\ln \left[t \cdot \sqrt{-R^{2}+r_{0}^{2}}+\sqrt{\left(-R^{2}+r_{0}^{2}\right) t^{2}-R^{2}}\right] \cdot r_{0}^{4}- \\
& -\frac{1}{2} r_{0}^{3} \cdot \operatorname{arctg} \frac{\left(2 i \cdot R^{2}-2 i \cdot r_{0}^{2}\right)(t+i)-2 r_{0}^{2}}{2 r_{0} \sqrt{\left(-R^{2}+r_{0}^{2}\right)(t+i)^{2}+\left(2 i \cdot R^{2}-2 i \cdot r_{0}^{2}\right)(t+i)-r_{0}^{2}}}+ \\
& +\frac{1}{2} r_{0}^{3} \cdot \operatorname{arctg} \frac{\left(-2 i \cdot R^{2}+2 i \cdot r_{0}^{2}\right)(t-i)-2 r_{0}^{2}}{2 r_{0} \sqrt{\left(-R^{2}+r_{0}^{2}\right)(t-i)^{2}+\left(-2 i \cdot R^{2}+2 i \cdot r_{0}^{2}\right)(t-i)-r_{0}^{2}}} .
\end{aligned}
$$

\section{Application and discussion}

The engineering strain range $\varepsilon$ during upsetting by radial dies can be found through displaced volumes, namely:

$$
\varepsilon=\left(V / V_{w p}\right) \cdot 100 \%
$$

Obviously, the exact (strict) solution does not have a completed form, which requires finding acceptable assumptions for use in calculating the engineering strain range in a given operation. At present calculations use the approximate equation:

$$
\varepsilon^{*}=\frac{\left(H_{0}-h_{m i d}\right)}{H_{0}} \cdot 100 \% ; h_{m i d}=\frac{H+(3 / 4) h}{2} .
$$

Formula (18) is a robust equation for calculating the engineering strain at the upsetting of cylindrical workpieces by radial dies. 


\section{Conclusions}

Thus the main difficulty in the refined calculations of the displaced volume in the processes of upsetting of workpieces by radial dies consists in the search for the volume of the region enclosed between the contact surface and the boundaries of the transverse convexities. The results of the methods of calculating the displaced volume at upsetting of workpieces by radial dies, in the long term, can be compared with the experimental data.

\section{References}

1. Z. Sun, J. Cao, H. Wu, Z. Yin, Journal of Materials Processing Technology (2018) (to be published), DOI: 10.1016/j.jmatprotec.2017.11.019.

2. A. Leacock, G. Volk, D. McCracken, D. Brown, Procedia Engineering, 183, 343-350 (2017), DOI: 10.1016/j.proeng.2017.04.050.

3. L.S. Nielsen, S. Lassen, C.B. Andersen, J. Grønbæk, N. Bay, Journal of Materials Processing Technology, 71 (1), 36-42 (1997), DOI: 10.1016/S0924-0136(97)00140-4.

4. V.V. Kukhar, R.S. Nikolenko, V.A. Burko, Metallurgical and Mining Industry, 1, 1824 (2016), http://www.metaljournal.com.ua/assets/Journal/englishedition/MMI_2016_1/4_Kukhar.pdf.

5. D.M. Shlychkova, N.I. Vatin, Construction of Unique Buildings and Structures, 3 (54), 34-46 (2017), (rus), DOI: 10.18720/CUBS.54.3.

6. M. Wang, D. Li, F. Wang, X. Zang, X. Li, H. Xiao, F. Du, F.C. Zhang, Z. Jiang, Engineering Failure Analysis, 59, 197-210, (2016), DOI: $10.1016 /$ j.engfailanal.2015.10.005.

7. J. Kajtoch, Metallurgy and Foundry Engineering, 33 (1), 51-61 (2007), DOI: 10.7494/mafe.2007.33.1.51.

8. A.N. Levandovskiy, B.E. Melnikov, A.A. Shamkin, Magazine of Civil Engineering, 1, 3-22 (2017), DOI: 10.18720/MCE.69.1.

9. R. Matsumoto, Y. Osumi, H. Utsunomiya, Journal of Materials Processing Technology, 214 (3), 651-659 (2014), DOI: 10.1016/j.jmatprotec.2013.10.011.

10. D.Y. Yang, Y. Choi, J.H. Kim, International Journal of Machine Tools and Manufacture, 31 (3), 397-404 (1991), DOI: 10.1016/0890-6955(91)90084-G.

11. V. Kukhar, V. Artiukh, A. Butyrin, A. Prysiazhnyi, Advances in Intelligent Systems and Computing, 692, 201-211 (2018), DOI: 10.1007/978-3-319-70987-1_22.

12. V. Kukhar, V. Artiukh, A. Prysiazhnyi, A. Pustovgar, E3S Web of Conference, 33, 02031 (2018), DOI: 10.1051/e3sconf/20183302031.

13. V.A. Tyurin, A.L. Sapunov, Steel in Translation, 44 (3), 190-195 (2014), DOI: $10.3103 / \mathrm{S} 0967091214030164$.

14. S.Y. Lin, Journal of Materials Processing Technology, 123 (1), 36-41 (2002), DOI: $10.1016 / \mathrm{S} 0924-0136(02) 00035-3$.

15. L. Zaharia, R. Comaneci, R. Chelariu, D. Luca, Materials Science and Engineering: A, 595, 135-142 (2014), DOI: 10.1016/j.msea.2013.12.006.

16. V.V. Karpov, O.V. Ignat'ev, A.A. Semenov, Magazine of Civil Engineering, 6, $147-$ 160 (2017), DOI: 10.18720/MCE.74.12.

17. A.S. Semenov, S.S. Semenov, B.E. Melnikov, V.S. Tikhonov, Magazine of Civil Engineering, 6, 78-101 (2017), DOI: 10.18720/MCE.74.8. 
18. A.A. Semenov, I.A. Porivaev, D.V. Kuznetcov, T.H. Nguen, A.S. Saitgalina, E.S. Tregubova, Construction of Unique Buildings and Structures, 8(59), 7-26. (2017), (rus), DOI: 10.18720/CUBS.59.1.

19. A.L. Hoffmanner, Metal forming: interrelation between theory and practice; proceedings of a symposium on the relation between theory and practice of metal forming (Cleveland, Ohi, 1970), DOI: 10.1007/978-1-4615-1757-3.

20. A.V. Grushko, V. V. Kukhar, Yu. O. Slobodyanyuk, Solid State Phenomena, 265, 114-123 (2017), DOI: 10.4028/www.scientific.net/SSP.265.114.

21. V.V. Kukhar, O.V. Vasylevskyi, Metallurgical and Mining Industry, 3, 71-78 (2014), http://www.metaljournal.com.ua/assets/Archive/en/MMI3/14.pdf. 